\section{Screening and Characterization of 11 Novel Microsatellite Markers from Viburnum dilatatum}

\author{
Deborah Dean and Phillip A. Wadl \\ Department of Entomology and Plant Pathology, University of Tennessee, \\ 2431 Joe Johnson Drive, Knoxville, TN 37996
}

\section{Xinwang Wang}

Texas AgriLife Research and Extension Center, Texas A\&M University, System, 17360 Coit Road, Dallas, TX 75252

\section{William E. Klingeman}

Department of Plant Sciences, University of Tennessee 2431 Joe Johnson Drive, Knoxville, TN 37996

\author{
Bonnie H. Ownley \\ Department of Entomology and Plant Pathology, University of Tennessee, \\ 2431 Joe Johnson Drive, Knoxville, TN 37996
}

Timothy A. Rinehart

USDA-ARS, Southern Horticultural Laboratory, 810 Highway 26 West, Poplarville, MS 39470

\section{Brian E. Scheffler}

USDA-ARS-CGRU MSA Genomics Laboratory, 141 Experiment Station Road, Stoneville, MS 39470

\section{Robert N. Trigiano ${ }^{1}$ \\ Department of Entomology and Plant Pathology, University of Tennessee, 2431 Joe Johnson Drive, Knoxville, TN 37996}

Additional index words. Adoxaceae, genomic library, ornamentals, invasive species, polymorphism information content, SSRs

\begin{abstract}
Viburnum dilatatum is a popular and economically important ornamental shrub. The wide range of desirable horticultural traits, paired with a propensity for seedlings to become invasive, has created interest in the genetics and breeding of this species. To investigate the genetic diversity of $V$. dilatatum, microsatellite loci were identified from a GT-enriched genomic library constructed from $\boldsymbol{V}$. dilatatum 'Asian Beauty'. Eleven microsatellite loci have been characterized on a group of 16 different related $V$. dilatatum cultivars and hybrids. Two to 12 alleles were identified per locus, and the polymorphism information content (PIC) values ranged from 0.36 to 0.87 . Expected heterozygosity $\left(\mathrm{H}_{\mathrm{e}}\right)$ ranged from 0.48 to 0.88 and observed heterozygosity $\left(\mathrm{H}_{\mathrm{o}}\right)$ ranged from 0 to 0.73 . This set of molecular markers also exhibited expected transferability between various $V$. dilatatum cultivars and two hybrids with $V$. japonicum. As a consequence, these markers will aid in breeding for new cultivar development, assist with early detection and screening of plants that have escaped cultivation, and are expected to help in refining the phylogenetic relationship of $V$. dilatatum to other species and genera within the Adoxaceae.
\end{abstract}

The genus Viburnum includes more than 160 species of shrubs and small trees distributed widely throughout the Northern hemisphere and into the Southern hemisphere (Winkworth and Donoghue, 2004). Collectively, Viburnum species provide many ideal year-round ornamental qualities. The attractive flowers and glossy green leaves of spring and summer give way to an array of bright berries and vibrant fall foliage with colors ranging from yellow to red to dark purple. The multiseasonal allure of plants in this genus makes Viburnum an important ornamental plant crop to the U.S. nursery industry. Total sales of Viburnum were \$19,500,000 in 1998 (U.S. Dept. of Agr., 1998), and sales increased to $\$ 24,647,000$ in 2007 (USDA-NASS, 2010). Growing awareness and ongoing breeding efforts have led to increasing consumer demand for viburnum shrubs. Viburnum dilatatum, a common and versatile species that is native to Asia, was introduced to the United States in 1846 and is valued for its vibrant fall color, leaf color retention, and outstanding cherryred fruit production that persists into winter. For these reasons, it has become increasingly prevalent in horticultural commerce (Dirr, 2007). At maturity, the shrub reaches 1.5 to $3.0 \mathrm{~m}$ ( 5 to 10 feet) tall and exhibits lustrous dark green leaves.

There are striking diversity among horticultural characteristics in Viburnum species, including leaf shape, fruit and flower color, fertility, and plant growth habit (Dirr, 2007; Winkworth and Donoghue, 2004). Erected by Linnaeus in 1753, the genus has undergone more than 10 taxonomic revisions, and despite those classification efforts, evolutionary relationships and geographical relatedness of the species have been largely unaddressed (Winkworth and Donoghue, 2005). Winkworth and Donoghue (2005) combined molecular data using two chloroplast genes ( $\operatorname{trn} K$ intron and $p s b A-\operatorname{trn} H$ IGS) and three nuclear loci (nrIts, WAXY1, and WAXY2) to provide a biogeographical analysis of the genus. Although 12 well-supported species groups, or clades, were identified using the molecular data, issues within this eclectic genus still linger. For example, the relationship between the section Pseudotinus and the species $V$. clemensiae and $V$. urceolatum is not well supported. In addition, the rates of diversification remain unclear, and there is a persistent lack of resolution at the base of the phylogenetic tree (Winkworth and Donoghue, 2004, 2005). Not surprisingly, a plethora of cultivars and hybrids further complicate the organization of this vast genus (Dirr, 2007).

Although many ornamental plants, including $V$. dilatatum, make important contributions to regional environmental health and diversity, certain non-native species have escaped cultivation and are causing economic damage. During a period of 85 years (1906 to 1991), 79 exotic plant species have been deemed responsible for almost $\$ 97$ billion in damages in the United States (Office of Technology Assessment, 1993). Many of the plants listed on invasive species lists such as Celastrus orbiculatus, Euonymus alatus, and Pyrus calleryana remain economically important and popular nursery plants (The University of Georgia, 2010). Regardless, invasive plants cause significant economic damage and can lead to considerable reductions in populations of native flora and fauna, often in response to competition for limited resources (Anonymous, 2008). Unfortunately, current methods of nonnative plant management, which include physical removal, herbicidal and biological control methods, have not been practical or effective in controlling extensive proliferation of many invasive ornamental plants ( $\mathrm{Li}$ et al., 
2004). Indeed, the increase in commercial availability of potentially problematic plants makes early characterization of potential pest plants and their cultivars a high priority. The New Jersey Invasive Species Strike Team placed $V$. dilatatum on a 2010 Watch List of invasive species that identifies plants that may pose a threat to native plant communities (Anonymous, 2010). Viburnum dilatatum can form thickets after escaping cultivation that may displace or prevent growth of less competitive native herbs, shrubs, and trees. Shrubs yield an abundance of viable seed from a typically heavy seasonal fruit set (Dirr, 2007). In turn, viable seeds aid in the rapid colonization of land previously not colonized with $V$. dilatatum.

Some invasive species, including $V$. dilatatum, may be difficult to discern from native vegetation (Anonymous, 2008). Dirr (2007) stated that $V$. dilatatum is difficult to identify based on foliage, because some specimens may have branches with two differently shaped leaves comingling. Indeed, $V$. dilatatum has been observed along the woodland edges of the National Arboretum, often growing undetected until old enough to display their unmistakable red fruits (J. Feely, personal communication). Moreover, there is anecdotal evidence to suggest that $V$. dilatatum may be escaping cultivation and hybridizing with the natively occurring $V$. dentatum (J. Feely, personal communication). This caveat necessitates the availability of a reliable method for identification of this popular ornamental shrub and its hybrids.

A group identified as the Invasive Plant Research and Partnerships with Ornamental Horticulture and Natural Resource Management convened for a workshop in 2008 to discuss the problem of invasive plant species. Research areas were identified and included the following priorities: develop scientific means to evaluate the persistence and spread of invasive plants; enhance detection methods for invasive taxa; and acquire a means to identify invasive species, cultivars, and hybrids of cultivars such as genetic markers (Anonymous, 2008). Molecular markers provide a means of meeting these criteria.

Molecular tools have become a superior method for interspecific and intraspecific hybrid analysis and cultivar identification of ornamental plants (Pounders et al., 2007; Wadl et al., 2008, 2009; Wang et al., 2010). Microsatellites are ubiquitous throughout genomes and codominant markers, often used in both interspecific and intraspecific diversity studies (Gupta and Varshney, 2000). These genetic markers exhibit hypervariabilty and are easily detected using polymerase chain reaction (PCR) and two unique primers (Powell et al., 1996). Microsatellite markers are ideal for identification and genetic fingerprinting of plants because of the high levels of polymorphism they possess (Datta et al., 2010). Based on searches of the literature and GenBank, there is a dearth of microsatellite markers that can be applied to the genus Viburnum. In this study, we created a small insert genomic library from $V$. dilatatum 'Asian Beauty' using a biotin enrichment protocol (Wang et al., 2007). From the library, 11 polymorphic markers were developed and used to characterize a group of $V$. dilatatum accessions and cultivars. It is envisioned that these markers will be useful in discerning taxonomic relationships and will be used in future efforts to track and identify the origins of $V$. dilatatum plants within populations that have escaped cultivation.

\section{Materials and Methods}

Genomic DNA from unopened flower buds or young leaves of 16 samples (Table 1) was extracted using DNeasy ${ }^{\circledR}$ Plant Mini Kit (Qiagen, Germantown, MD) and quantified using a NanoDrop ${ }^{\circledR}$ ND-1000 ultraviolet-Vis Spectrophotometer (NanoDrop Technologies, Wilmington, DE). The quality of DNA was visually assessed on $2 \%$ agarose gels, stained with ethidium bromide, and visualized in a 2000 Gel Doc System (Bio-Rad Laboratories, Hercules, CA). Microsatellite sequences were attained from the genomic library and enriched for $(\mathrm{GT})_{\mathrm{n}}$ using biotin hybridization based on previous methods by Wang et al. (2007). DNA $(2.5 \mu \mathrm{g})$ was digested at $37^{\circ} \mathrm{C}$ for 5 min with AluI, HaeIII, RsaI, and StuI to generate blunt-end fragments that ranged from 250 to $800 \mathrm{bp}$. Fragments were ligated to SNX linkers and recovered using the SNX forward primer adaptors: 5' CTAAGGCCTTGCTAG CAGAAGC 3' and 3'AAAAGATTCCGGAA CGATCGTCTTCGp 5' (Hamilton et al., 1999). Column-purified PCR products were hybridized to $(\mathrm{GT})_{12}$ biotinylated oligonucleotides to enrich fragments that contained (GT) microsatellite sequences (QIAquick PCR purification Kit, Valencia, CA). Streptavidin Magnesphere ${ }^{\circledR}$ Paramagnetic Particles (Promega, Madison, WI) were used to capture the biotinylated desired motifs (Hamilton et al., 1999; Wang et al., 2004, 2007). The enriched PCR fragment products were column-purified and ligated to the EcoRV digested pBluescript II SK $(+)$ vector, (Stratagene, Hanover, MD) at an $8: 1$ insert to vector ratio. The vector and ligated enriched simple sequence repeat-containing fragments were transformed into Escherichia coli TOP 10 Electrocomp ${ }^{\mathrm{TM}}$ cells (Invitrogen, Carlsbad, CA) using the Gene Pulser Xcell ${ }^{\circledR}$ Electroporation System (Bio-Rad, Hercules, $\mathrm{CA})$ and then grown in petri dishes containing Luria-Bertani-ampicillin (LB) medium and the indicator IPTG and X-gal following the manufacturer's recommendations. The petri dishes were then incubated overnight at $37{ }^{\circ} \mathrm{C}$ and evaluated for color expression and cell growth (Sambrook et al., 1989).

Detection of putative microsatellites within the cloned DNA fragments was completed as previously described (Wang et al., 2007) with minor modifications. Cells from white colonies with putative inserts were placed in a 10 $\mu \mathrm{L}$ PCR reaction mixture containing $1 \times \mathrm{PCR}$ gold buffer, $0.2 \mathrm{~mm}$ dNTPs, $2.0 \mathrm{~mm} \mathrm{MgCl}_{2}$, 0.3 U AmpliTaq Gold DNA polymerase (Applied Biosystems, Foster City, CA), $0.25 \mathrm{~mm}$ each of the following three primers: T3, T7, and $(\mathrm{GT})_{12}$, and sterile water. Conditions during PCR were: one cycle at $96{ }^{\circ} \mathrm{C}$ for $2 \mathrm{~min}$ followed by 35 cycles of $94{ }^{\circ} \mathrm{C}$ for $1 \mathrm{~min}$, $50{ }^{\circ} \mathrm{C}$ for $1 \mathrm{~min}, 72^{\circ} \mathrm{C}$ for $1 \mathrm{~min}$, and one cycle of $72{ }^{\circ} \mathrm{C}$ for $1 \mathrm{~min}$. PCR amplicons were visualized on a $2 \%$ agarose gel containing ethidium bromide. Amplicons with a DNA smear were considered putatively positive for having a microsatellite insert (Wang et al., 2007). Colonies of interest were collected and duplicated in $100 \mu \mathrm{L}$ of LB-ampicillin freezing medium (Sambrook et al., 1989). Plasmid DNA from the putative positive colonies was isolated using a modified alkaline lysis method and was sequenced (ABI Big-Dye Version 3.1 terminators) on a Model ABI 3730XL capillary electrophoresis DNA sequencer (Applied Biosystems).

Putative microsatellite-containing colonies were sequenced $(n=198), 47$ primer pairs were designed from the resultant sequences using Primer 3.0 (Rozen and Skaletsky, 1998), and synthesized by Integrated DNA Technologies (Coralville, IA). Primer pairs were optimized for PCR using DNA from $V$. dilatatum 'Asian Beauty' and 'Erie'. Microsatellite amplification was completed using the following $10-\mu \mathrm{L}$ PCR reaction mixture: $4 \mathrm{ng}$ of genomic

Table 1. Accessions of Viburnum dilatatum and other taxa and their sources.

\begin{tabular}{|c|c|}
\hline Species/cultivars/forma analyzed & Specimen origin/accession number ${ }^{2}$ \\
\hline V. dilatatum & NA 56670 \\
\hline V. dilatatum & NA 80690 \\
\hline V. dilatatum 'Asian Beauty' & NCSU \\
\hline V. dilatatum 'Asian Beauty' & MA $503-99 * 1$ L-31/52-07 \\
\hline$(V$. japonicum $\times V$. dilatatum 'Catskill') 'Chippewa' & $\mathrm{NCSU}$ \\
\hline V. dilatatum 'Erie' & NCSU \\
\hline V. dilatatum 'Erie' & MA $784-2005 * 176-10$ \\
\hline V. dilatatum 'Henneke' & MA $153-2004 * 1 \mathrm{M}-43 / 12-47$ \\
\hline V. dilatatum forma hispidum & AA $1120-86 * \mathrm{~B}$ \\
\hline$V$. dilatatum 'Iroquois' & MA $640-2006 * 1$ FF-016/70-95 \\
\hline$V$. dilatatum forma pilosulum & NA 55216 \\
\hline V. dilatatum forma pilosulum & NA 66267 \\
\hline$V$. dilatatum forma pilosulum & AA $77-90 * B$ \\
\hline$V$. dilatatum forma pilosulum & AA $36-72 *$ A \\
\hline$V$. dilatatum 'Michael Dodge' & NCSU \\
\hline$(V$. japonicum $\times V$. dilatatum $)$ 'Fugitive' & NCSU \\
\hline
\end{tabular}

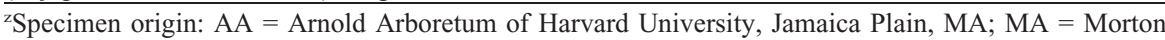
Arboretum, Lisle, IL; NA = National Arboretum, Washington, DC; NCSU = Department of Horticultural Science, North Carolina State University, Raleigh, NC. 
DNA, $0.25 \mu \mathrm{M}$ forward and reverse primers, $2.0 \mathrm{mM} \mathrm{MgCl}_{2}, 0.2 \mathrm{~mm}$ dNTPs, $1 \times$ PCR gold buffer, $0.4 \mathrm{U}$ AmpliTaq Gold DNA polymerase, and sterile water. The following PCR conditions were used: one cycle of $94^{\circ} \mathrm{C}$ for 3 min and 35 cycles of $94^{\circ} \mathrm{C}$ for $40 \mathrm{~s}, 58^{\circ} \mathrm{C}$ for $40 \mathrm{~s}, 72^{\circ} \mathrm{C}$ for $30 \mathrm{~s}$, and one cycle of $72^{\circ} \mathrm{C}$ for $4 \mathrm{~min}$. The PCR products were sized on the QIAxcel Capillary Electrophoresis System (Qiagen) using a 25- to 300-bp DNA size ladder. Unambiguous reproducible electropherograms were generated from all loci. The raw allele length data were placed into allelic classes using FlexiBinV2, an automated microsatellite binning program that converts raw allele size data into allelic size classes (Amos et al., 2007). A conservative \pm 2 -bp allele size determination error rate was used as a result of the 2-bp resolution limitation of the QIAxcel ethidium-based system to allow reproducibility between various laboratories and to avoid false inflation of diversity within the data. Of these, the 11 primer pairs (Table 2) that amplified the greatest number of microsatellite alleles were selected for analysis of 16 different accessions of $V$. dilatatum and related taxa. Allele sizes can vary by only one or 2 bps, which can lead to errors in placing alleles into the proper allelic class when the size is rounded. The resulting allelic classes were used to determine the number of alleles per locus. Twenty-three of the loci were polymorphic. However, the 11 most polymorphic loci (Table 2) were selected to analyze 16 different accessions of $V$. dilatatum and related taxa (Table 1). After converting the raw data to allelic classes, the number of alleles per locus $(A), \mathrm{H}_{\mathrm{e}}, \mathrm{H}_{\mathrm{o}}$, PIC for all microsatellite loci were calculated using PowerMarker Version 3.23 software (Liu and Muse, 2005). Deviations from the Hardy-Weinberg equilibrium were calculated using GENEPOP Version 4.0.10 (Rousset, 2008).

\section{Results and Discussion}

A total of 81 alleles were observed across the 11 loci. The number of alleles per locus ranged from two (VD006, VD0017) to 11 (VD005, VD012, VD014) and the mean value was 7.36. Observed heterozygosity values were 0 to 0.73 and $\mathrm{H}_{\mathrm{e}}$ ranged from 0.48 to 0.88 . All loci, except for VD004, had $\mathrm{H}_{\mathrm{o}}$ values that were lower than the $\mathrm{H}_{\mathrm{e}}$. The majority of our markers did not conform to Hardy-Weinberg equilibrium (Table 2) as a result of the nonrandom mating and clonal reproduction that occurs with selection of plants for specific characteristics in cultivar development. The PIC values of the microsatellite loci VD006 and VD017 were 0.36; all other loci had PIC values greater than 0.50 .

This set of microsatellite markers had a high level of polymorphism and genetic diversity. The ability of a set of molecular markers to delineate between different cultivars depends on the level of polymorphism that can be detected (Datta et al., 2010). In a study of the usefulness of codominant markers in linkage analysis studies, markers were described as being highly informative if PIC values were greater than 0.50 , and the majority of this group of markers meet these criteria (Botstein et al., 1980). Additionally, the number of alleles per loci was another important factor in determining the usefulness of markers. Loci with many alleles and PIC values close to 1.0 are most informative and provide the most value in linkage map analyses (Botstein et al., 1980). We intend to use our markers to assess cross-transferability to other Viburnum species. If future work reveals cross-amplification to other taxa, these markers are expected to be useful for identifying Viburnum species, hybrids, and resolving phylogenetic relationships among species in the genus.

Correct identification of plant species and hybrid parentage is essential for breeding programs and patent protection. Moreover, early and accurate identification of invasive species could be a useful tool in combating plant invasiveness. As more ornamental plant cultivars, including selections that offer reproductive sterility, are developed and become available, germplasm identification will become more complex. Inaccurate identification of plants can be problematic throughout botanic gardens and commercial nurseries in the United States. Using plastid sequences, most specimens of a popular fern marketed as Cheilanthes wrightii were in fact the prolific self-regenerating species, $C$. distans (Pryer et al., 2010). Accurate identification can reduce mislabeling in the nursery and assist in germplasm management. Moreover, accurate and early identification is important when investigating plant species with invasive potential. Before establishment in the environment, many invasive species undergo lag periods of varying length, during which time between the species' initial arrival and rapid colonization of a new area may be delayed. A study of alien woody plant species revealed that $51 \%$ of all plants had lag periods extending up to 200 years with shrubs having a mean lag period of 131 years (Kowarik, 1995). Conversely, certain invasive plant species such as Schefflera actinophylla presented a short lag period of only 17 years (Daehler, 2009). Microsatellite markers have become a useful tool for identifying plants in the ornamental horticultural trade as well as for food crops (Bassil et al., 2010; Wadl et al., 2008).

Accurate characterization and identification of some Viburnum species, however, may be confounded in the absence of distinct morphological characteristics presented by fruit and flowers making $V$. dilatatum and its cultivars and hybrids difficult to identify while in their juvenile stage. Indeed, Viburnum species generally have juvenility periods lasting from 1 to 3 years (Thomas G. Ranney, personal

Table 2. Characterization of 11 microsatellite loci isolated from Viburnum dilatatum 'Asian Beauty'.

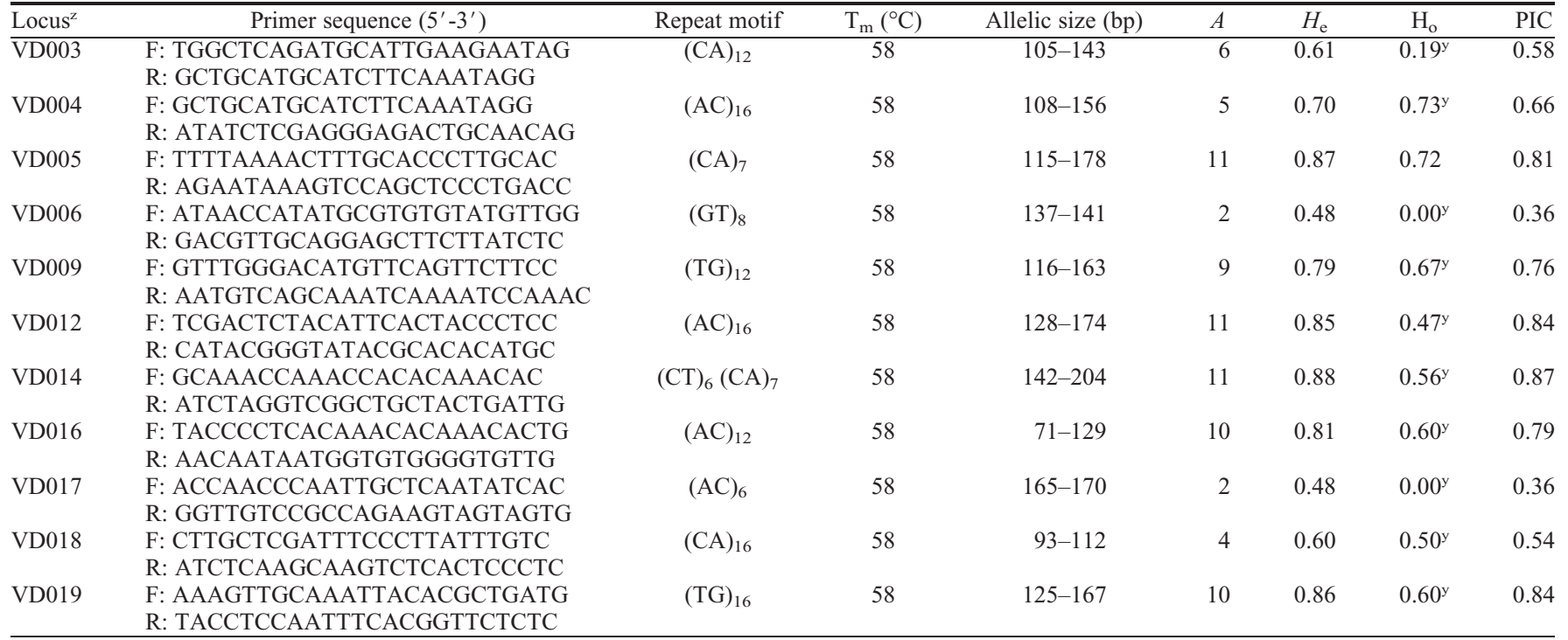

${ }^{\mathrm{z}}$ GenBank accession numbers HQ997898-HQ997908.

${ }^{\mathrm{y}}$ Significant deviation from Hardy-Weinberg equilibrium $(P<0.05)$.

$T_{m}=$ annealing temperature; $A$ = allele numbers per locus; $\mathrm{H}_{\mathrm{e}}=$ expected heterozygosity; $\mathrm{H}_{\mathrm{o}}=$ observed heterozygosity; PIC = polymorphic information content 
communication). If genetic tools were available, both the environmental lag time and juvenility periods (before seedlings mature and produce seeds) would be ideal times during which potential rogue plants could be detected and screened. Genetic fingerprinting with molecular markers provides an efficient and effective alternative to plant characterization using biological markers, which are limited through transitive influences of both the environment and developmental stages of the plant (Romero et al., 2009). Indeed, microsatellites have been found to have use in studying invasive plant species (Pashley et al., 2006).

In conclusion, our microsatellite markers have much potential for identifying $V$. dilatatum, its cultivars, and possibly its hybrids. We expect that this set of microsatellite markers will help provide DNA fingerprints for future cultivars and be useful in marker-assisted selection, gene mapping, population genetics, and identification of Viburnum species with invasive potential. Furthermore, these loci may provide insight into the work on phylogeny by Winkworth and Donoghue (2005) and help refine the current sections within Viburnum.

\section{Literature Cited}

Amos, W., J.I. Hoffmann, A. Frodsham, L. Zhang, S. Best, and A.V.S. Hill. 2007. Automated binning of microsatellite alleles: Problems and solutions. Mol. Ecol. Notes 7:10-14.

Anonymous. 2008. Invasive Plant Research and Partnerships with Ornamental Horticulture and Natural Resource Management Workshop report. U.S. National Arboretum, Washington, DC. $<$ http://usda.mannlib.cornell.edu/usda/current/ NursProd/NursProd-09-26-2007.pdfpage 9>.

Anonymous. 2010. New Jersey Invasive Species Strike Team 2010 plant list. 7 Jan. 2011. <http: //www.njisst.org/Index.asp>.

Bassil, N.V., M. Muminova, and W. Njuguna. 2010. Microsatellite-based fingerprinting of western blackberries from plants, IQF berries and puree. Acta Hort. 859:73-80.

Botstein, D., R.L. White, M. Skolnick, and R.W. Davis. 1980. Construction of a genetic linkage map in man using restriction fragment length polymorphisms. Amer. J. Hum. Genet. 32:314 331.

Daehler, C. 2009. Short lag times for invasive tropical plants: Evidence from experimental plantings in Hawaii. PLoS One 4:1-5.
Datta, J., N. Lal, M. Kaashyap, and P.P. Gupta. 2010. Efficiency of three PCR based marker systems for detecting DNA polymorphism in Cicer arietinum L. and Cajanus cajan L. Millspaugh. Genet. Eng. Biotechnol. J. 2010:1-15.

Dirr, M.A. 2007. Viburnums: Flowering shrubs for every season. Timber Press, Portland, OR.

Gupta, P.K. and R.K. Varshney. 2000. The development and use of microsatellite markers for genetics and plant breeding with emphasis on bread wheat. Euphytica 113:163-185.

Hamilton, M.B., E.L. Pincus, A. Di Fiore, and R.C. Fleischer. 1999. Universal linker and ligation procedures for construction of genomic DNA libraries enriched for microsatellites. Biotechniques 27:500-507.

Kowarik, I. 1995. Time lags in biological invasions with regard to the success and failure of alien species, p. 15-38. In: Pysek, P., K. Prach, M. Rjmanke, and M. Wade (eds.). Plant invasions: General aspects and special problems. SPB Academic Publishing, Amsterdam, The Netherlands.

Li, Y., Z. Cheng, W.A. Smith, D.R. Ellis, Y. Chen, X. Zheng, Y. Pei, K. Luo, D. Zhao, Q. Yao, and H. Duan. 2004. Invasive ornamental plants: Problems, challenges, and molecular tools to neutralize their invasiveness. Crit. Rev. Plant Sci. 23:381-389.

Liu, K. and S.V. Muse. 2005. PowerMarker: Integrated analysis environment for genetic marker data. Bioinformatics 21:2128-2129.

Office of Technology Assessment. 1993. Harmful non-indigenous species in the United States. Office of Technology Assessment, U.S. Congress, Washington, DC.

Pashley, C.H., J.R. Ellis, D.E. McCauley, and J.M. Burke. 2006. EST databases as a source for molecular markers: Lessons from Helianthus. J. Heredity. 97:381-388.

Pounders, C.T., T. Rinehart, and H. Sakhanokho. 2007. Evaluation of interspecific hybrids between Lagerstroemia indica and L. speciosa. HortScience 42:1317-1322.

Powell, W., G.C. Machray, and J. Provan. 1996. Polymorphism revealed by simple sequence repeats. Trends Plant Sci. 1:215-222.

Pryer, K.M., E. Schuettpelz, L. Huiet, A.L. Grusz, C.J. Rothfels, T. Avent, D. Schwartz, and M.D Windham. 2010. DNA barcoding exposes a case of mistaken identity in the fern horticultural trade. Mol. Ecol. Resources. 10:979-985.

Romero, G., C. Adeva, and Z. Battad. 2009. Genetic fingerprinting: Advancing the frontiers of crop biology research. Philippine Sci. Letters. 2:8-13.

Rousset, F. 2008. Genepop'007: A complete reimplementation of the Genepop software for
Windows and Linux. Mol. Ecol. Resources. 8: 103-106.

Rozen, S. and H.J. Skaletsky. 1998. Primer3. 1 Nov. 2010. <http://www.genome.wi.mit.edu/genome software/other/primer3.html $>$.

Sambrook, J., E.F. Fritsch, and T. Maniatis. 1989. Molecular cloning: A laboratory manual. Cold Spring Harbor Laboratory Press, Cold Spring Harbor, NY.

The University of Georgia. 2010. Center for Invasive Species and Ecosystem Health and National Park Service. Invasive plant atlas of the United States. 19 Oct. 2010. <http://www. invasiveplantatlas.org/about.html>

U.S. Dept. of Agr. 1998. 1998 Census of horticultural specialties. Washington, DC. 3 Dec. 2010.<http:// www.agcensus.usda.gov/Publications/1997/ Horticulture_Specialties/indexintro.aspU.S $>$.

USDA NASS. 2010. 7 Jan. 2011. <http://www. agcensus.usda.gov/Publications/2007/Online_ Highlights/Census_of_Horticulture/index.asp > .

Wadl, P.A., J.A. Skinner, J.R. Dunlap, S.M. Reed, T.A. Rinehart, V.R. Pantalone, and R.N. Trigiano. 2009. Honeybee-mediated controlled pollination in Cornus florida and C. kousa intraand interspecific crosses. HortScience 44: $1527-1533$

Wadl, P.A., X.W. Wang, A.N. Trigiano, J.A Skinner, M.T. Windham, and R.N. Trigiano. 2008b. Molecular identification keys for cultivars and lines of Cornus florida and C. kousa based on simple sequence repeat loci. J. Amer. Soc. Hort. Sci. 133:783-793.

Wang, X.W., D. Dean, P.A. Wadl, D. Hadziabdic, B.E. Scheffler, T. Rinehart, R. Cabrera, and R.N. Trigiano. 2010. Development of microsatellite markers from crape myrtle (Lagerstroemia L.). HortScience 45:842-844.

Wang, X.W., A. Kaga, N. Tomooka, and D.A. Vaughan. 2004. The development of SSR markers by an new method in plants and their application to gene flow studies in azuki bean. [Vigna angularis (Willd.) Ohwi \& Ohashi]. Theor. Appl. Genet. 109:352-360.

Wang, X.W., R.N. Trigiano, M.T. Windham, R.E. DeVries, B.E. Scheffler, T.A. Rinehart, and J.M. Spiers. 2007. A simple PCR procedure for discovering microsatellites from small insert libraries. Mol. Ecol. Notes 7:558-561.

Winkworth, R.C., and M.J. Donoghue. 2004. Viburnum phylogeny: Evidence from the duplicated nuclear gene GBSSI. Mol. Phylogenet. Evol. 33:109-126.

Winkworth, R.C., and M.J. Donoghue. 2005. Viburnum phylogeny based on combined molecular data: Implications for taxonomy and biogeography. Amer. J. Bot. 92:653-666. 